\title{
Improving the Mechanical Properties of the Fusion Zone in Electron-Beam Welded Ti-5Al-5Mo-5V-3Cr Alloys
}

\author{
CHRISTOPHER J. MARVEL, JOSEPH C. SABOL, TIMOTIUS PASANG, \\ MASASHI WATANABE, and WOJCIECH Z. MISIOLEK
}

It is well-known that $\omega$-phase precipitates embrittle Ti-5553 alloys and that $\omega$-phase embrittlement can be overcome with appropriate heat treatments. However, the microstructural evolution of electron-beam welded Ti-5553 is not as understood as compared to the cast or wrought material. This study compared the microstructures of as-welded and post-weld heat-treated specimens by scanning and transmission electron microscopy, and similarly compared the localized mechanical behavior of the fusion zones with microhardness testing and digital image correlation coupled tensile testing. The primary observations were that the embrittling $\omega$-phase precipitates formed upon cooling, and could not be fully solutionized in a single-step treatment of $1077 \mathrm{~K}\left(804^{\circ} \mathrm{C}\right)$ for 1 hour. It was also discovered that nanoscale $\alpha$-phase precipitates nucleated after the single-step treatment, although they were small in number and sparsely distributed. However, a two-step heat treatment of $1077 \mathrm{~K}\left(804{ }^{\circ} \mathrm{C}\right)$ for 1 hour and $873 \mathrm{~K}\left(600{ }^{\circ} \mathrm{C}\right)$ for 4 hours completely solutionized the $\omega$-phase and produced a dense network of $2-\mu$ m-wide $\alpha$-phase plates, which significantly improved the mechanical properties. Overall, this study has shown that post-weld heat treatments improve the strength and ductility of electron-beam welded Ti-5553 alloys by controlling $\omega$ - and $\alpha$-phase evolution.

DOI: $10.1007 / \mathrm{s} 11661-017-3968-2$

(C) The Minerals, Metals \& Materials Society and ASM International 2017

\section{INTRODUCTION}

Metastable Beta titanium ( $\beta$-Ti) alloys have become popular in the aerospace industry due to their favorable response to heat treatments, high strengths, low forging temperatures (in comparison to $\alpha+\beta$ alloys such as Ti-6Al-4V), deep hardenability, and relatively lower flow stresses. These characteristics make them well suited for applications requiring forged components with thick cross sections and high strengths. The metastable $\beta$ titanium alloys have a high enough $\beta$-stabilizer content to suppress a martensitic transformation when quenched from above the $\beta$-transus. At even higher $\beta$-stabilizer contents, 100 pct $\beta$-phase retention may be observed in some alloys. ${ }^{[1]}$ Because metastable $\beta$-Ti alloys do not transform martensitically upon cooling, they respond well to solution treatments and aging in the $\alpha+\beta$ phase field after quenching to precipitate $\alpha$. The size, morphology, and volume fraction of the $\alpha$ precipitates inherently control the mechanical properties.

CHRISTOPHER J. MARVEL, MASASHI WATANABE, and WOJCIECH Z. MISIOLEK are with the Department of Materials Science and Engineering, Lehigh University, Bethlehem, PA 18018. Contact e-mail: cjm312@lehigh.edu JOSEPH C. SABOL is with Alcoa, Pittsburgh, PA. TIMOTIUS PASANG is with the Department of Mechanical and Engineering, Auckland University of Technology, Auckland 1010, New Zealand.

Manuscript submitted September 7, 2016.

Article published online January 17, 2017
The Ti-5Al-5V-5Mo-3Cr (Ti-5553) system is one of the metastable $\beta$-Ti alloys that has emerged in the last two decades to replace Ti-10V-2Fe-3Al (Ti-10-2-3) for landing gear applications and thick section forgings, ${ }^{[2]}$ but has also found use in airframe components, flat products, and armor applications. ${ }^{[2-4]}$ In comparison, the Ti-5553 alloy has better forgability and response to heat treatment, is less prone to segregation, and can be air cooled to achieve sufficient hardening in thick sections. ${ }^{[1,2,4]}$ Similar to other metastable $\beta$ titanium alloys, Ti-5553 is susceptible to forming continuous grain boundary $\alpha$. Grain boundary $\alpha$ cannot be suppressed and leads to poor mechanical properties when improper thermomechanical processing is performed, such as insufficient deformation to breakup existing grain boundary $\alpha$, slow cooling from solution treatment temperatures, and extended durations at high solution treatment temperatures. In addition to grain boundary $\alpha$, metastable $\beta$-Ti alloys may also form $\omega$-phase precipitates during cooling and heating. The presence of $\omega$ is commonly linked to poor mechanical properties and brittle behavior. Heat treatments are generally performed above its transus temperature in order to eliminate it in the final microstructure. In relation to Ti-5553, $\omega$-phase precipitation has been shown to embrittle $\beta$-Ti alloys. Sabol et al. observed that $\omega$ was present in the fusion zone (FZ) of electron-beam welded (EBW) Ti-5553, and reported that it imparted brittle characteristics to the FZ because $\omega$-precipitates are obstacles for dislocation motion. ${ }^{[5]}$ Furthermore, the authors showed that a tri-layer ordering was present in 
the $\omega$-phase, which further increased its resistance to dislocation motion.

While metastable $\beta$-Ti alloys can attain high strength and good ductility due to their positive response to heat treatments, welding of such alloys locally alters the microstructure and erases the effects of any prior working or heat treatment. As a result, the mechanical properties are degraded in the weld zone. Depending on the $\beta$-stabilizer content of an alloy, $100 \operatorname{pct} \beta$ may be retained upon cooling in the FZ and heat-affected zones (HAZ) after welding. This has been shown to be the case in multiple metastable $\beta$-alloys, such as Ti-15V-3Cr-3Al-3Sn, Ti-8V-7Cr-3Al-1Zr, and Ti-8V-4Cr-2Mo-2$\mathrm{Fe}-3 \mathrm{Al},{ }^{[6]}$ as well as in Ti-5553. ${ }^{[7-9]}$ The retention of $\beta$ imparts deleterious properties, because the $\beta$-phase is not as strong as $\alpha$-phase or $\alpha$-strengthened $\beta$-phase, i.e., a $\beta$-matrix containing precipitated $\alpha$, and hence, subsequent heat treatments are imperative to impart strength to the weld zone. Becker and Baeslack ${ }^{[6]}$ reported that by heat treating the welded metastable $\beta$-Ti alloys mentioned previously, strength was reintroduced to the weldments without much penalty in elongation by precipitating $\alpha$.

Conversely, welded Ti-5553 has not yet received such attention. For unwelded Ti-5553, many researchers have investigated various heat treatments for Ti-5553 to further improve its mechanical properties. ${ }^{[10-16]}$ They have shown the implications of super- and sub-transus treatments, duplex treatments, interrupted cooling, fast cooling, slow cooling, and various other factors on the microstructural evolution and mechanical properties of Ti-5553. These treatments include common heat treatments, such as the beta-annealed slow cool age (BASCA) treatment, $\alpha+\beta$ solution treatment (ST), $\alpha+\beta$ solution treatment and age (STA), modified STA, aging, and stress relief, where the STA and aging have proven to impart the highest strength. ${ }^{[2,3]}$ However, these heat treatments or modifications thereof have not been applied to welded Ti-5553.

Therefore, the goal of this current work is to investigate strengthening and ductility of the FZ of EBW Ti-5553 after applying typical Ti-5553 ST and STA heat treatments found in the literature. ${ }^{[2,4]}$ The results of this work will provide insight into the response of Ti-5553 to EBW and subsequent heat treatments as well as promote wider implementation of Ti-5553 in future applications requiring joining, such as manufacturing continuous sheet, fabrication of complex structures, and weld repair of existing components. The microstructure and mechanical properties of Ti-5553 in the as-welded condition were previously reported elsewhere and are referenced for comparison. ${ }^{[5,9]}$ In this article, mechanical properties were measured after two PWHT paths, and microstructures at different stages of PWHTs were characterized by optical microscopy, scanning electron microscopy (SEM), transmission electron microscopy (TEM), and aberration-corrected scanning transmission electron microscopy (STEM). Finally, influences of microstructure evolution through the PWHTs to the mechanical behaviors will be discussed.

\section{EXPERIMENTAL PROCEDURE}

The elemental composition and $\beta$-transus $\left(\mathrm{T}_{\beta}\right)$ of Ti-5553 used in this study is shown in Table I. Autogenous electron-beam butt welds between 1.6-mm-thick sheets of Ti-5553 were made in the down-hand position using a welding voltage of $150 \mathrm{kV}$, a traverse speed of $8.5 \mathrm{~mm} / \mathrm{s}$, and a welding current of $3 \mathrm{~mA}$. Welded coupons were then subjected to one of the two PWHTs: heating at $1077 \mathrm{~K}\left(804^{\circ} \mathrm{C}\right)$ for 1 hour and followed by air cooling (referred hereafter as PWHT-1), and the same PWHT-1 with an additional aging treatment of heating at $873 \mathrm{~K}\left(600{ }^{\circ} \mathrm{C}\right)$ for 4 hours and air cooling (PWHT-2). Afterwards, cross-sectional samples in the as-welded and PWHT conditions were ground and polished down to $0.05 \mu \mathrm{m}$ colloidal silica, etched with Kroll's reagent $(100 \mathrm{~mL}$ water $+2 \mathrm{~mL} \mathrm{HF}+5 \mathrm{~mL}$ $\mathrm{HNO}_{3}$ ), and analyzed with light optical microscopy.

Vicker's hardness profiles across the welds were made using a Leco microindentation hardness tester with a load of 300 grams. Tensile tests on sub-size dog-bone tensile specimens, in accordance with ASTM E8M-04 and with the weld located perpendicular to the tensile axis, were conducted with a crosshead speed of $3 \mathrm{~mm} / \mathrm{min}$. A non-contact 3-dimensional image correlation photogrammetry system, known as ARAMIS, was employed to evaluate the full field strain distribution in the vicinity of the welds during tensile testing. Details of this procedure can be found elsewhere. ${ }^{[9,17,18]}$ Post-mortem fracture surfaces were observed by SEM and also metallographically prepared to observe the fracture path through the sample cross section.

Electron-transparent thin specimens for STEM were prepared via the in situ liftout method with an FEI Scios DualBeam focused ion beam (FIB) instrument. Specimens were extracted from single grain regions along the $\langle 110\rangle$ or $\langle 111\rangle$ crystal orientations to conduct imaging and diffraction analysis in TEM and STEM. The FIB-cut specimens were cleaned using a Fischione 1040 NanoMill operated at $900 \mathrm{eV}$ to remove the surface damage layer that is induced during FIB thinning. Selected area diffraction (SAD) patterns were acquired in a JEOL JEM-2000FX TEM instrument operated at $200 \mathrm{kV}$. High-resolution bright-field (BF) and high-angle annular dark-field (HAADF) STEM imaging was conducted in a probe-corrected JEOL JEM-ARM200CF instrument at an operating voltage of $200 \mathrm{kV}$. All specimens were plasma-cleaned prior to loading to the STEM instrument for characterization to limit carbon build-up contamination.

\section{RESULTS}

\section{A. Macroscopic Observation of FZ}

The light optical micrographs shown in Figure 1 highlight the macrostructures of the EBW Ti-5553 in the as-welded and PWHT conditions. Each condition exhibited columnar grain morphologies in the FZs and equiaxed grain morphologies in the HAZs. Furthermore, the FZs and HAZs in the as-welded samples 
Table I. Chemical Composition of Ti-5553 in Weight Percent

\begin{tabular}{lccccccccr}
\hline Material & $\mathrm{O}$ & $\mathrm{N}$ & $\mathrm{Al}$ & $\mathrm{V}$ & $\mathrm{Mo}$ & $\mathrm{Cr}$ & $\mathrm{Fe}$ & $\mathrm{Ti}$ & $\mathrm{T}_{\beta}$ \\
\hline Ti-5Al-5V-5Mo-3Cr & 0.14 & $<0.01$ & 5.03 & 5.10 & 5.06 & 2.64 & 0.38 & bal. & $1133 \mathrm{~K}\left(860{ }^{\circ} \mathrm{C}\right)$ \\
\hline
\end{tabular}
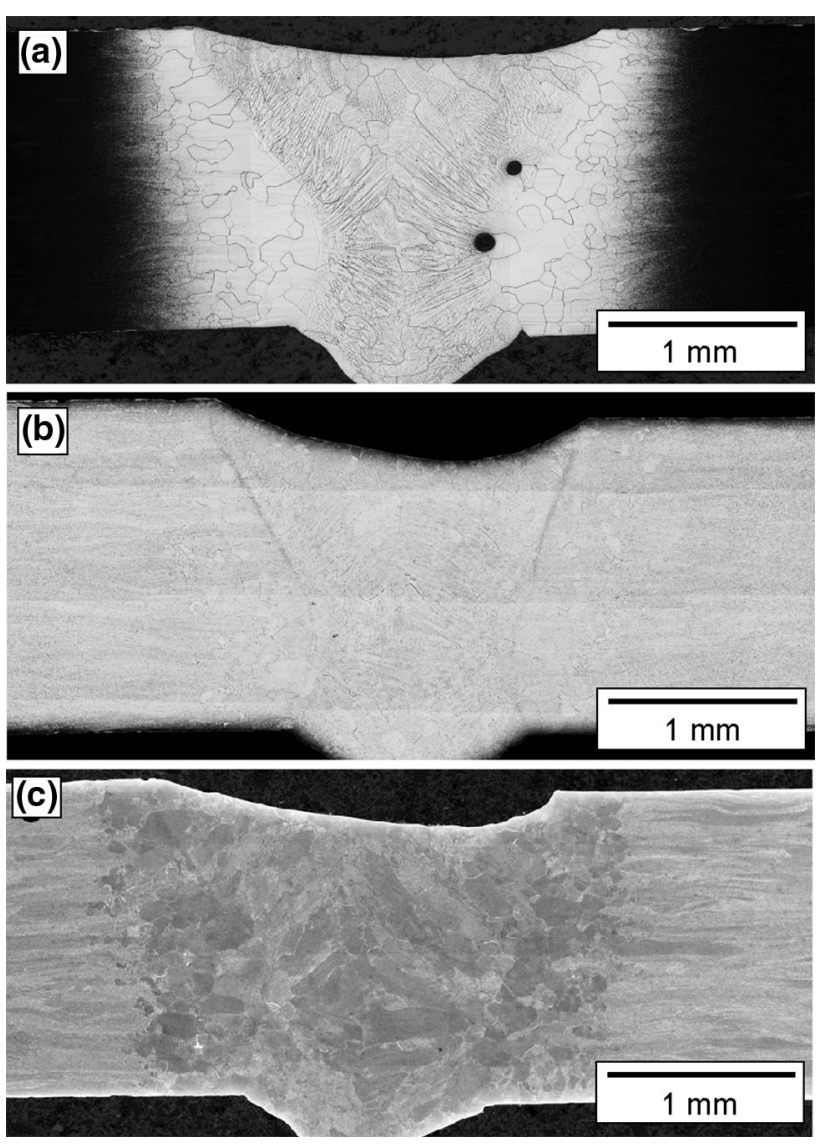

Fig. 1-Light optical micrographs showing the base metal and weld zone of the $(a)$ as-welded specimen, $(b) 1077 \mathrm{~K}\left(804^{\circ} \mathrm{C}\right) / 1 \mathrm{~h}$ solution-treated specimen, and $(c) 1077 \mathrm{~K}\left(804^{\circ} \mathrm{C}\right) / 1 \mathrm{~h}$ solution-treated specimen that was additionally aged at $873 \mathrm{~K}\left(600^{\circ} \mathrm{C}\right) / 4 \mathrm{~h}$. Part (a) is reprinted with permission from Ref.[8].

exhibited retained $\beta$. A previous investigation by Sabol et al. provides a more detailed description of the as-welded microstructure. ${ }^{[9]}$ Contrary to the as-welded condition, both PWHT-1 and PWHT-2 exhibited precipitated $\alpha$ in both the $\beta$-grains and along the $\beta$-grain boundaries. Higher magnification backscatter electron images of the FZs from PWHT-1 and PWHT-2 are shown in Figure 2, where $\alpha$-precipitates appear darker and the $\beta$-matrix appears brighter. PWHT- 1 resulted in a sparse network of coarse, blocky $\alpha$-plates in the $\beta$-grains and continuous/semi-continuous grain boundary $\alpha$. PWHT-2 similarly resulted in a sparse network of coarse, blocky $\alpha$ in the $\beta$-grains and grain boundary $\alpha$, but also a dense network fine $\alpha$ among the coarse $\alpha$-plates in the grain interiors. Similar results have been reported by Kar and Settefrati. ${ }^{[12,16]}$
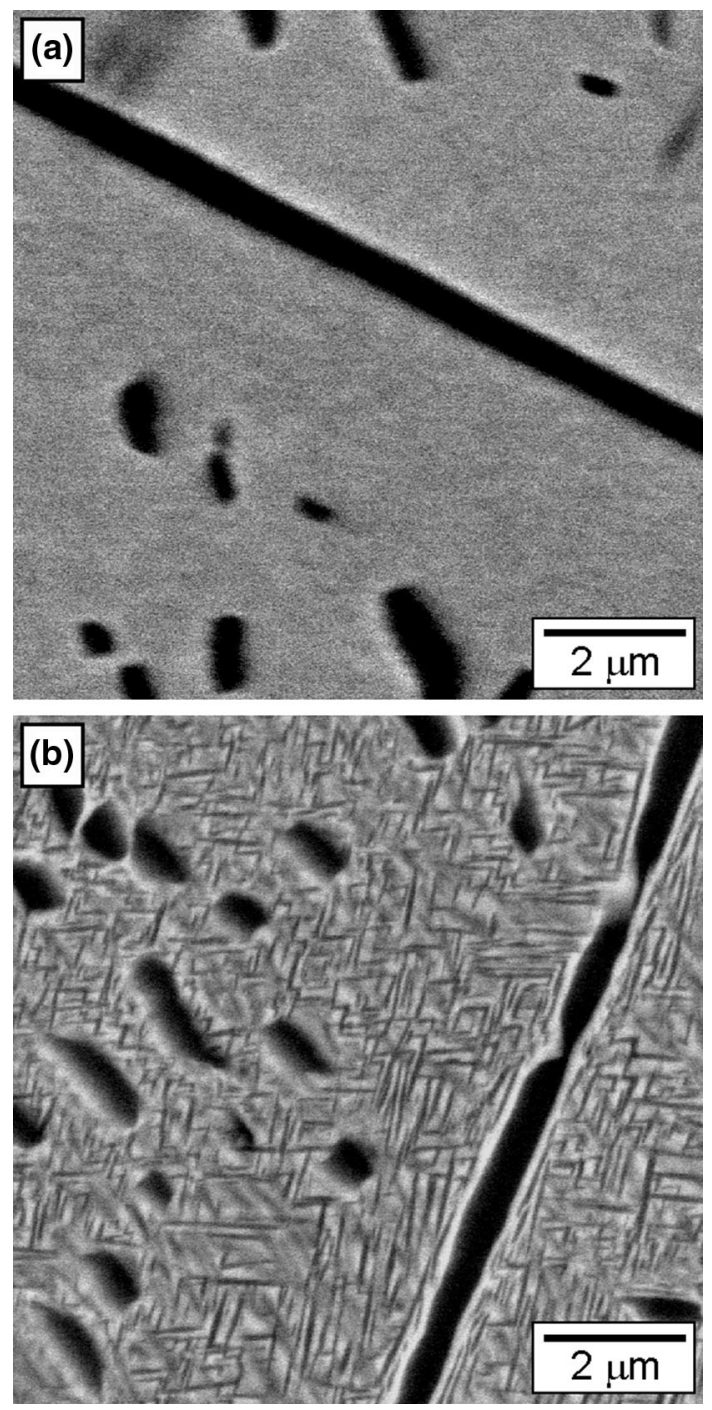

Fig. 2-Backscatter scanning electron micrographs displaying the size and distribution of $\alpha$ precipitates in the $(a) 1077 \mathrm{~K}\left(804^{\circ} \mathrm{C}\right) / 1 \mathrm{~h}$ solution-treated and $(b) 1077 \mathrm{~K}\left(804{ }^{\circ} \mathrm{C}\right) / 1 \mathrm{~h}$ solution-treated and aged at $873 \mathrm{~K}\left(600{ }^{\circ} \mathrm{C}\right) / 4 \mathrm{~h}$ specimens. Note, the $873 \mathrm{~K}\left(600{ }^{\circ} \mathrm{C}\right) / 4 \mathrm{~h}$ aged sample exhibited a bi-modal distribution of $\alpha$ precipitates.

\section{B. Mechanical Property Measurement of EBW Samples}

The effects of EBW and PHWTs on hardness are shown in Figure 3. Vicker's hardness line profiles were collected on each specimen and each data point reflects a single hardness measurement. Focusing on the as-welded condition, the FZ exhibited a lower hardness than the surrounding $\mathrm{BM}$, thereby indicating that the welding process led to diminished mechanical 


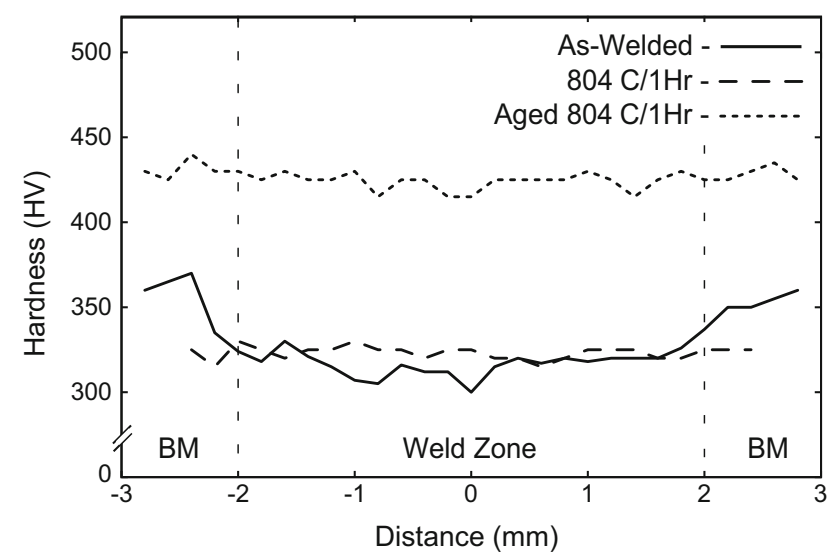

Fig. 3-Vicker's microhardness profiles across the weld region of each heat-treated specimen. The edges of the weld zone are identified by the dashed vertical lines.

properties. In addition, the FZ of the as-welded condition exhibited the lowest average hardness $(\sim 315 \mathrm{HV})$ among all three heat treatments, while PWHT-2 exhibits the highest average hardness $(\sim 430 \mathrm{HV})$. These results correspond well to the observed microstructures of FZs in the as-welded and PWHT samples. The as-welded specimen did not contain any strengthening phases while PWHT-2 contained a dense network of fine $\alpha$. Conversely, the hardness in the PWHT-1 FZ ( 320 HV) remained almost same as that of the FZ in the as-welded condition, despite containing some $\alpha$-precipitates. This poor improvement could be due to the precipitation of sparsely dispersed coarse $\alpha$-precipitates, which would not act as effective pinning factors for dislocation motion in the softer $\beta$-phase.

Tensile tests provided further evidence of the effects of PWHT on the as-welded FZ of EBW Ti-5553. Every tensile specimen, regardless of condition, failed in the FZ and displayed little evidence of plasticity. Figures 4(a) through (c) show the fracture paths on post-mortem polished cross sections. The as-welded specimen failed along the fusion line (i.e., interface between the FZ and HAZ) and PWHT-1 and PWHT-2 failed along the weld center lines. In addition, Figures 4(d) through (f) show the post-mortem fracture surfaces in secondary electron SEM images. In each case, both transgranular and intergranular fracture were observed as the grain structure changed along the fracture path. Three-dimensional image correlation photogrammetry performed simultaneously during tensile tests further showed the effects of microstructure as a result of EBW and PWHTs. Figure 5 shows the localized strain distribution in the weld zone while under tension prior to failure. The localized strain distribution is a result of the significantly different microstructures (i.e., weld zone vs base metal), which developed as a result of EBW and PWHT (Figure 1). The white intensity in each strain map corresponds to the most highly strained regions that reach nearly $\sim 6.5$ pct strain. The intensity scale is also kept constant across all three specimens. In this case, the as-welded sample exhibited the highest local strain distribution in the weld zone, and
PWHT-2 was the most successful in reducing the localized strain.

The average true stresses at failure for the as-welded, PWHT-1, and PWHT-2 conditions were $735,{ }^{[5]} 647$, and $873 \mathrm{MPa}$, respectively. In agreement with their corresponding microstructures, the as-welded FZs exhibited lower fracture stresses than those in the solution-treated and aged condition. Again, this lower fracture stress can be attributed to the retained $\beta$-phase in the FZ of the as-welded condition and the fine $\alpha$-precipitates in PWHT-2. The PWHT-1 samples, however, exhibited lower fracture stress than those in the as-welded condition. This result does not correlate with the hardness trends, but does correlate with the microstructures making up each FZ. The main difference between the microstructure observed in the FZ of the as-welded condition and that in PWHT-1 is the presence of coarse $\alpha$ and grain boundary $\alpha$. Continuous $\alpha$ at the $\beta$-grain boundaries has been shown to lead to poor tensile properties and intergranular-like fracture. ${ }^{[19,20]}$ In addition, EBW significantly increased the grain size in the FZ compared to the starting material and caused $\alpha$ to go into solution, whereas both PWHTs precipitated $\alpha$, although in different morphologies and amounts compared to the starting material. While solution treatment and/or aging did not affect the base metal grain size, the PWHTs precipitated $\alpha$ and allowed strain to be more evenly distributed across the gage length of the tensile specimens compared to the as-welded specimens.

\section{DISCUSSION}

\section{A. Correlation Between FZ Microstructure and Mechanical Properties}

As a result of EBW and the two PWHTs, the microstructures and mechanical properties varied according to their thermal history. Specimens in the as-welded condition comprised retained $\beta$, specimens subjected to PWHT- 1 contained coarse $\alpha$, and specimens subjected to PWHT-2 contained both coarse and fine $\alpha$. The hardness values of the FZs in the as-welded, PWHT-1, and PWHT-2 conditions were 315, 320, and $430 \mathrm{HV}$, respectively. The tensile strengths were measured to be 735,647 , and $873 \mathrm{MPa}$ for the as-welded, PWHT-1, and PWHT-2 conditions, respectively. There is slight discrepancy in the trend between hardness and tensile strength. In the following discussion section, potential reasons for the discrepancy will be explored based on detailed microstructure characterizations.

The microstructures observed in Figure 6 are representative of the microstructures obtained from EBW, PWHT-1, and PWHT-2 where each condition exhibited a different microstructure. In the as-welded condition, $\beta$ was retained in the FZ as a result of fast cooling from above the $\beta$-transus and having a sufficiently high $\beta$-stabilizer content ( 5 wt pet Mo, 5 wt pet V, 3 wt pet $\mathrm{Cr})$ which suppresses $\alpha$-precipitation and martensite formation during cooling and promotes the stabilization of the $\beta$-phase. The PWHT specimens exhibited continuous $\alpha$-layers at the $\beta$-grain boundaries and $\alpha$-plates in 

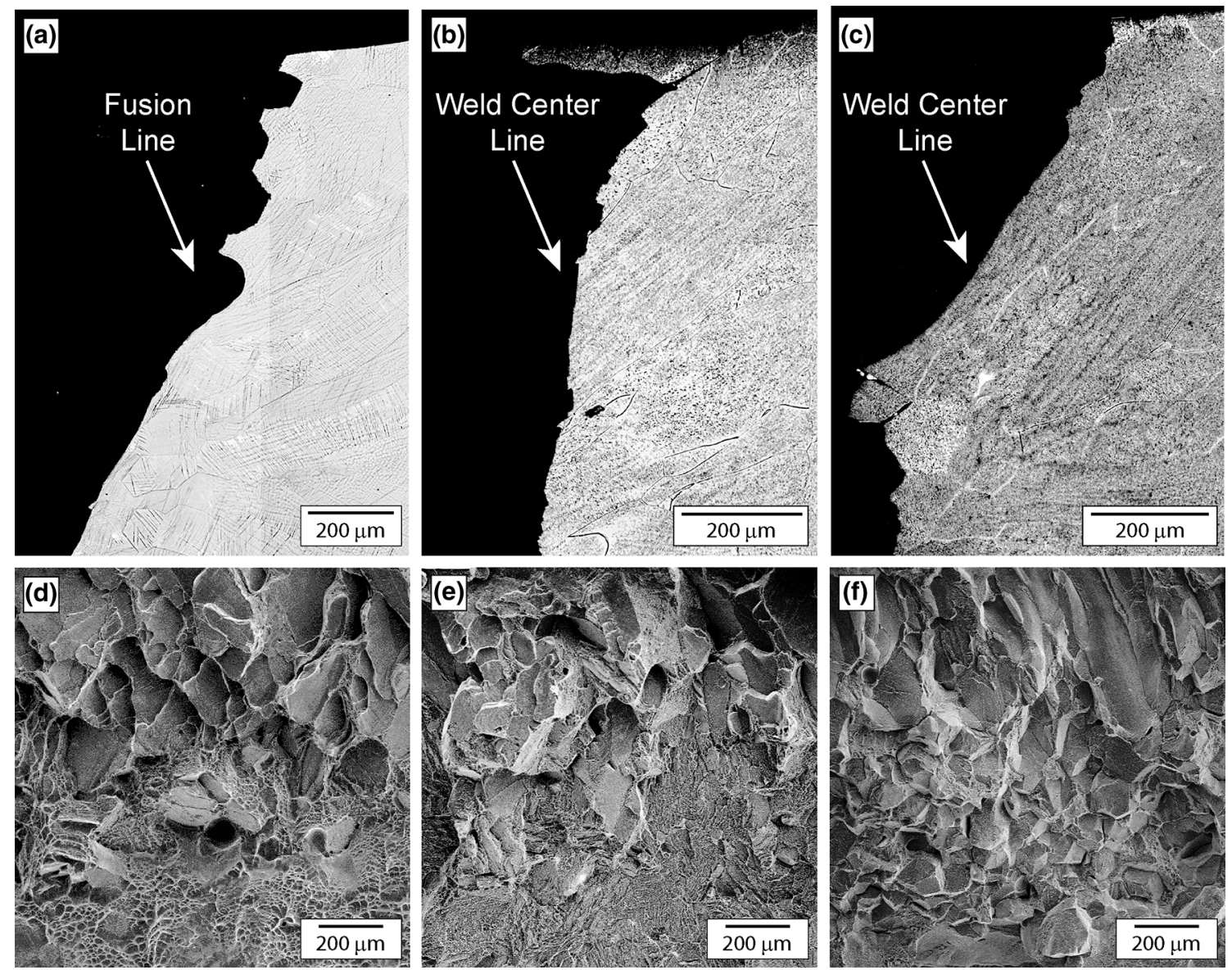

Fig. 4 - $(a$ through $c)$ Light optical micrographs showing the cross sections of the fracture surfaces from tensile specimens in the as-welded, $1077 \mathrm{~K}\left(804{ }^{\circ} \mathrm{C}\right) / 1 \mathrm{~h}$ solution-treated, and $1077 \mathrm{~K}\left(804^{\circ} \mathrm{C}\right) / 1 \mathrm{~h}$ solution-treated and aged at $873 \mathrm{~K}\left(600{ }^{\circ} \mathrm{C}\right) / 4 \mathrm{~h} \mathrm{specimens}$, respectively. $(d$ through $f$ ) SEM images of the fracture surfaces corresponding to images (a) through (c).

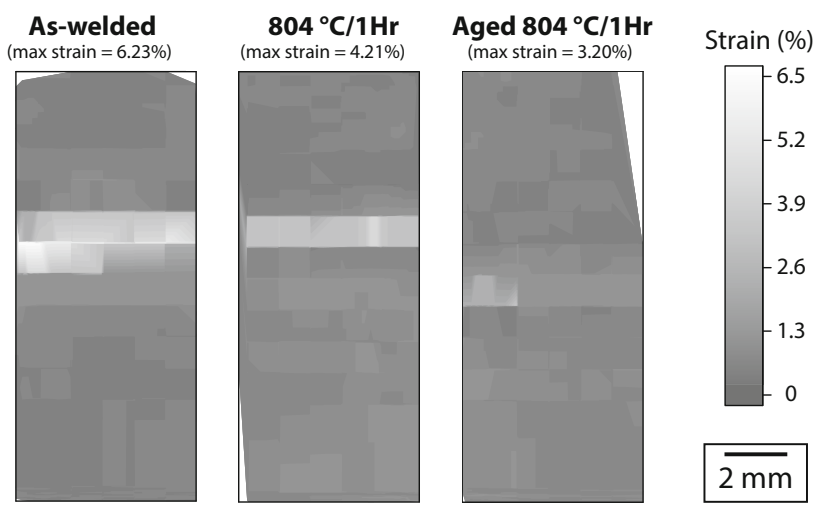

Fig. 5-Localized strain distribution prior to fracture during tensile tests captured by 3-dimensional image correlation photogrammetry. All strain values are in percent. The localized strain distribution took the shape of the weld zone, and the strain localization was less severe from left (as-welded) to right $\left[1077 \mathrm{~K}\left(804{ }^{\circ} \mathrm{C}\right) / 1 \mathrm{~h}\right.$ solution-treated and aged at $\left.873 \mathrm{~K}\left(600^{\circ} \mathrm{C}\right) / 4 \mathrm{~h}\right]$ as a result of post-weld heat treatments.

the $\beta$-grains. Coarse $\alpha$-plates precipitated in the $\beta$-grain interiors of the FZs in PWHT-1 and PWHT-2 specimens as a result of solution treating at $1077 \mathrm{~K}\left(804^{\circ} \mathrm{C}\right)$ for 1 hour. These coarse $\alpha$-precipitates were sparsely distributed throughout. The main differences between the FZ microstructures of PWHT-1 and PWHT-2 are the presence, size, and distribution of the secondary $\alpha$-plates observed in PWHT-2 specimens. The secondary $\alpha$-plates precipitated in the $\beta$-grains among the coarse $\alpha$-precipitates as a result of aging at $873 \mathrm{~K}\left(600^{\circ} \mathrm{C}\right)$ for 4 hours. At higher temperatures, the $\beta$-phase becomes more stable and $\alpha$ less stable. Furthermore, heat treating at a temperature high in the $\alpha+\beta$ field [i.e., $1077 \mathrm{~K}$ $\left.\left(804{ }^{\circ} \mathrm{C}\right)\right]$ will result in a low volume fraction of coarse $\alpha$ and a correspondingly high volume fraction of $\beta$. Conversely, heat treating at a relatively lower temperature in the $\alpha+\beta$ field [i.e., $873 \mathrm{~K}\left(600{ }^{\circ} \mathrm{C}\right)$ ] will result in a comparatively higher volume fraction of $\alpha$, which also produces a finer particle size and denser distribution.

The hardness and tensile results can be explained in terms of microstructure as it pertains to the as-welded and PWHT specimens. The as-welded FZs consist of retained $\beta$, which has a body-centered cubic (BCC) crystal structure, whereas the PWTH-1 and PWHT-2 FZs contain both $\beta$ and $\alpha$ (hexagonal close packed (HCP)), the latter acting as strengthening precipitates. Here, the presence of $\alpha$ alone is not sufficient to significantly strengthen the FZ in relation to the as-welded condition. The morphology, size, and distribution of $\alpha$ contribute greatly to the mechanical 
properties. This is evidenced in PWHT-1, where the hardness of the FZ is $320 \mathrm{HV}$ compared to $315 \mathrm{HV}$ in the as-welded FZ because the large $\alpha$-precipitates were too sparse to strengthen the $\beta$-matrix. Furthermore, the tensile strength associated with PWHT-1 is lower than that of the as-welded specimens, while the tensile strength of PWHT-2 was found to be greater than both the as-welded and PWHT-1 conditions. The dense network of comparatively fine $\alpha$-precipitates among the coarse $\alpha$-precipitates in PWHT-2 provides strength in contrast to the retained $\beta$ in the as-welded condition and only the coarse $\alpha$ in PWHT-1. In general, retained $\beta$ in the as-welded FZ is appreciably softer than the precipitation-strengthened $\beta$ in the solution-treated and aged (PWHT-2) FZ. This is due to the greater number of uninhibited slip systems in a continuous BCC crystal compared to the inhibited slip systems in a HCP precipitation-strengthened $\mathrm{BCC}$ crystal. The dense network of fine $\alpha$-precipitates in the PWHT-2 FZs provides obstacles for dislocation slip through the BCC $\beta$-phase, which significantly increases the hardness and strength of the FZ.

Further indication of the effect of microstructure on the mechanical properties of the FZ was observed in the localized strain distribution during tensile testing. Figure 5 shows that the magnitude of localized strain accumulation within the weld zone decreased from the as-welded condition to the PWHT-1 condition and further to the PWHT-2 condition. As the volume fraction of $\alpha$ in the FZ increased, the magnitude of the localized strain accumulation decreased. This is a result of a more homogeneous microstructure across the weld zone in relation to the base metal (BM). Not only was the FZ microstructure altered during PWHT-1 and PWHT-2, but that of the BM was also affected. Figure 6 shows backscattered electron images of the FZ and BM from as-welded, PWHT-1, and PWHT-2 specimens. These images illustrate the effects of EBW and PWHTs on the FZ and BM. In all but the as-welded specimens, the FZ microstructures were similar to the concomitant BM microstructures, however, not identical. Resultant FZs and BMs microstructures of PWHT-1 consisted of a sparse network of coarse, blocky $\alpha$-plates in the $\beta$-grains and continuous/ semi-continuous grain boundary $\alpha$-layers. PWHT-2 resulted in a sparse network of coarse, blocky $\alpha$ in the $\beta$-grains and continuous/semi-continuous grain boundary $\alpha$-layers, as well as a dense network fine $\alpha$ among the coarse $\alpha$-plates in the grain interiors. The main difference between the FZs and BMs is the beta grain size and alpha morphology. The beta grains of the BM are significantly smaller and the alpha is more globular and not as prevalent as alpha layers at the grain boundaries. These features lend themselves to lessening the magnitudes of localized strain in the weld zone, as shown in Figure 5, due to the elimination of a sharp microstructural change from $\mathrm{BM}$ to $\mathrm{FZ}$ compared to the as-welded condition.

Even though the PWHTs imparted marked effects in both hardness and tensile strength compared to the as-welded condition, the hardness and tensile results cannot be correlated. PWHT-2 imparted improvements in both hardness and strength compared to the as-welded condition, but still fractured in a brittle manner during tensile testing. PWHT-1 imparted little benefit in hardness and a deleterious effect to tensile strength in relation to the as-welded condition, but fractured in a brittle manner like PWHT-2. The reason why hardness and tensile strength cannot be correlated is due to the differences between hardness testing and tensile testing. While both tests are, to some extent, measures of a material's resistance to deformation, the hardness test locally deforms the material and the tensile test globally deforms the material. To this point, the hardness test puts the material in local compression, which does not capture the bulk effects of microstructure, whereas tensile testing does.

\section{B. Influence on PWHTs to $\omega$ Phase}

It is well-known that the $\omega$-phase imparts brittle behavior in Ti alloys. ${ }^{[1,21,22]}$ Dislocations must shear through the $\omega$-phase during deformation, which is more difficult than simple dislocation climb especially when compared to the $\beta$-matrix that surrounds the $\omega$-phase precipitates. Therefore, the $\omega$-phase must be eliminated to reduce embrittlement in the FZ and to improve mechanical properties.

As shown in the SAD patterns in Figure 7, $\omega$ was observed in the FZ of EBW Ti-5553, which directly led to the embrittlement of as-welded specimens. The SAD patterns were acquired along the $[113]_{\beta}$ zone axis, wherein reflections and pronounced streaking corresponding to $\omega$ are evident at $1 / 3(\overline{2} 11)_{\beta}$ and $2 / 3(\overline{2} 11)_{\beta}$ and from $(000)$ to the $(\overline{2} 11)_{\beta}$ reflections in the FZs of as-welded specimens and PWHT-1, respectively. Jones et al. showed similar streaking in $[113]_{\beta}$ zone axis patterns from Ti-5553 identical to that observed in this work, and reported that it was due to the presence of $\omega .{ }^{[23]}$ It should be noted that these indications of $\omega$ were not found in the SAD patterns for the PWHT-2 specimens, confirming that $\omega$ is no longer present. These results suggest that 1 hour at $1077 \mathrm{~K}\left(804{ }^{\circ} \mathrm{C}\right)$ is insufficient to cause complete dissolution of $\omega$. However, subsequent thermal treatments, like aging at $873 \mathrm{~K}$ $\left(600{ }^{\circ} \mathrm{C}\right)$ for 4 hours, completely dissolved $\omega$ or provided proper conditions for its consumption by $\alpha$-precipitation, which has been shown by $\mathrm{Nag}$ and Deurig. ${ }^{[24-26]}$

In addition to the existence of $\omega$ in the as-welded FZ, the $\omega$-phase possibly exhibited three-fold atomic ordering. A more thorough discussion of the potential $\omega$-phase ordering in the as-welded specimen is found elsewhere. ${ }^{[5]}$ In general, dislocation motion is more restricted in ordered compounds than disordered phases. Shearing of the ordered compound by a dislocation would disrupt the order and a large energy barrier would need to be overcome to do so. Therefore, the three-fold atomic ordering discovered in the $\omega$-phase precipitates of this study likely invokes a larger embrittling effect compared to $\omega$-phase precipitates found in other $\mathrm{Ti}$ alloys that do not exhibit three-fold ordering. 

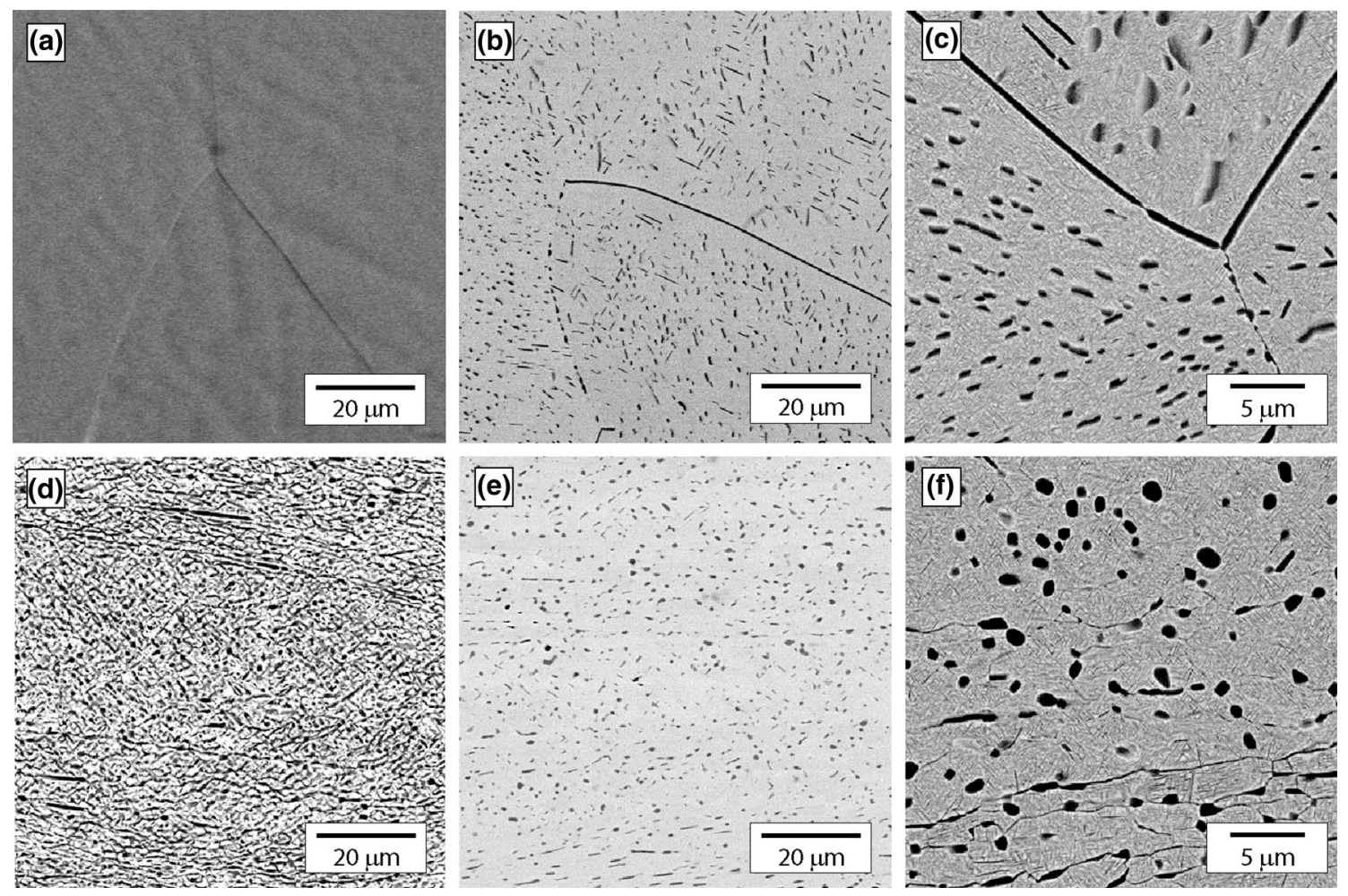

Fig. 6-Backscatter scanning electron micrographs comparing the microstructures of the fusion zones $(a$ through $c)$ and base metals $(d$ through $f)$ in the $(\mathrm{a}, \mathrm{d})$ as-welded $(\mathrm{b}, \mathrm{e}) 1077 \mathrm{~K}\left(804{ }^{\circ} \mathrm{C}\right) / 1 \mathrm{~h}$ solution-treated, and $(\mathrm{c}, \mathrm{f}) 1077 \mathrm{~K}\left(804{ }^{\circ} \mathrm{C}\right) / 1 \mathrm{~h}$ solution-treated and aged at $873 \mathrm{~K}\left(600{ }^{\circ} \mathrm{C}\right) /$ $4 \mathrm{~h}$.
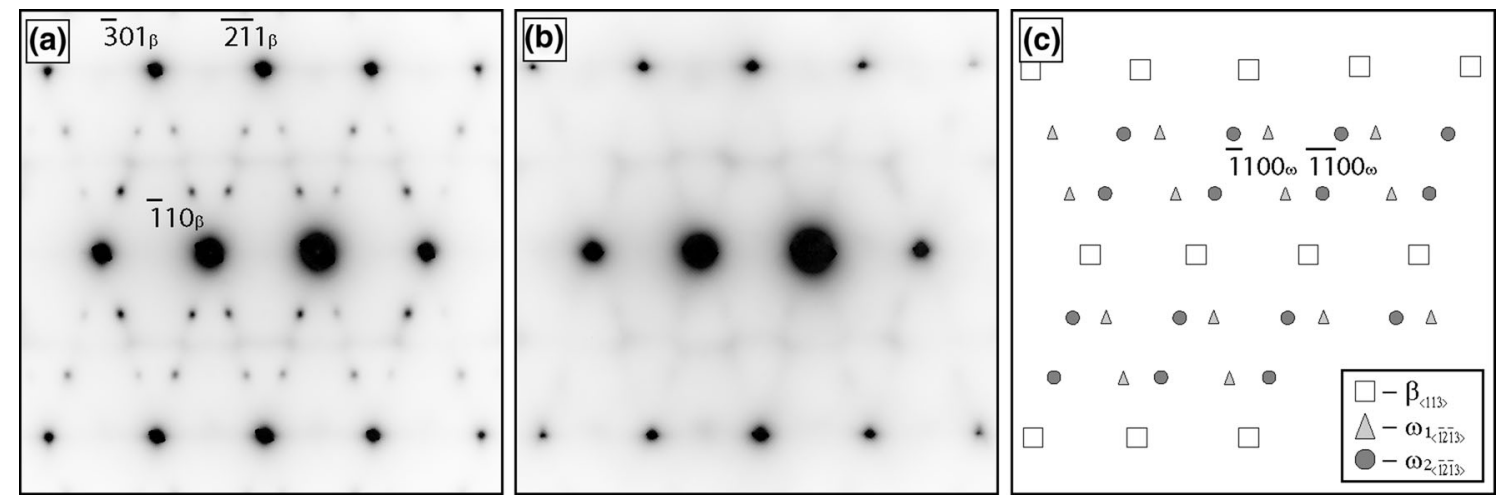

Fig. 7-Selected area diffraction patterns taken from the $[113]_{\beta}$ direction from the fusion zone of the $(a)$ as-welded and $(b) 1077 \mathrm{~K}\left(804{ }^{\circ} \mathrm{C}\right) / 1 \mathrm{~h}$ heat-treated samples. The diffraction spots of $\beta$ are labeled in (a) and the schematic shown in $(c)$ labels the $\omega$ diffraction spots.

\section{Influence on PWHTs to $\alpha$-Phase}

Further investigation of the PWHT specimens by TEM confirmed the presence of coarse $\alpha$ in the FZs of PWHT-1 and PWHT-2 specimens. To confirm the presence of fine $\alpha$ in the FZs, a combination of selected area diffraction and BF-STEM imaging was used. The SAD patterns shown in Figure 8 were collected with the specimens tilted to the $[111]_{\beta}$ zone axis, and with a small SAD aperture that isolated circular regions of $300 \mathrm{~nm}$ in diameter that did not exhibit coarse $\alpha$ to illuminate diffraction signal from the fine $\alpha$-precipitates. The PWHT-1 specimen (Figure 8(a)) did not exhibit any fine $\alpha$-reflections, contrary to the reflections seen in the
PWHT-2 specimen (Figure 8(b)), in which fine $\alpha$ was clearly shown in Figure 2(b). However, the BF-STEM image of PWHT-1 in Figure 9, where the TEM specimen was oriented on the $[110]_{\beta}$ direction, clearly shows several nanoscale $\alpha$-precipitates. The SAD pattern unlikely shows evidence of the nanoscale $\alpha$ in the solution-treated specimen because the diffracting volume of the $\alpha$ precipitates was too small to contribute to the diffraction pattern. To confirm that these nanoscale phases are $\alpha$, Figure 10 compares unfiltered HAADFSTEM images of the nanoscale $\alpha$ precipitates in PWHT-2 (Figures 10(a) and (c)), and the fine $\alpha$ in the solution-treated and aged specimens (Figures 10(b) and 


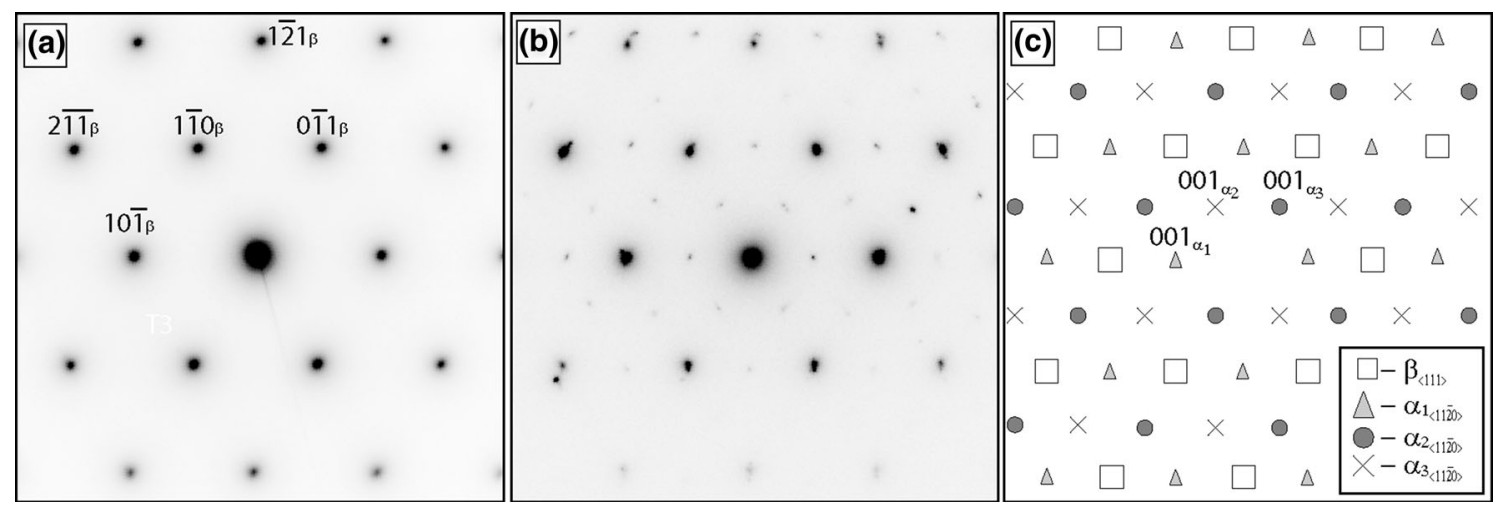

Fig. 8 - Selected area diffraction patterns from $[111]_{\beta}$ direction from the fusion zone of the $(a) 1077 \mathrm{~K}\left(804{ }^{\circ} \mathrm{C}\right) / 1 \mathrm{~h}$ solution-treated and $(b)$ $1077 \mathrm{~K}\left(804{ }^{\circ} \mathrm{C}\right) / 1 \mathrm{~h}$ solution-treated and aged at $873 \mathrm{~K}\left(600^{\circ} \mathrm{C}\right) / 4 \mathrm{~h}$ specimens. The diffraction spots of $\beta$ are labeled in (a) and the schematic shown in $(c)$ labels the $\alpha$ diffraction spots.

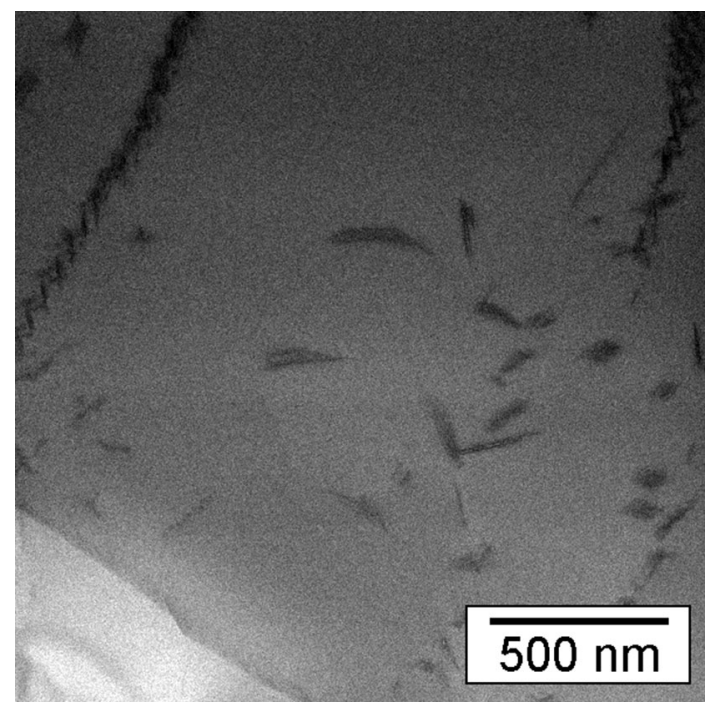

Fig. 9-Bright field STEM image of fine, inhomogeneously distributed $\alpha$ precipitates (dark) near a coarse $\alpha$ particle (light — bottom left) identified in the $1077 \mathrm{~K}\left(804^{\circ} \mathrm{C}\right) / 1 \mathrm{~h}$ solution-treated specimen.

(d)). It is clear that both sets of precipitates (i.e., fine $\alpha$ and nanoscale $\alpha$ ) have the same crystal structure and orientation relationship with respect to the B matrix.

These nanoscale $\alpha$ particles likely precipitated either along dislocations or on $\omega$-precursors, which can explain their inhomogeneous distribution. At $1077 \mathrm{~K}$ $\left(804{ }^{\circ} \mathrm{C}\right)$, competing transformations are occurring in the $\beta$-matrix; $\omega$ is being dissolved into the $\beta$-matrix and $\alpha$ is precipitating and growing out of the $\beta$-matrix. As these events are simultaneously occurring, their frequency of occurrence is random and likely dependent on one another. Nag et al. and Duerig et al. showed that $\alpha$ precipitated at $\beta / \omega$ interfaces and dislocations in Ti-5553 and Ti-10-2-3 alloys. ${ }^{[24,26]}$ Duerig et al. described the disruption of the lattice at the $\beta / \omega$ interface and at dislocations and reported them to be sites for $\alpha$ precipitation. In the same work, Duerig et al. also explained that as the temperature increased closer to the $\beta$-transus, the precipitation of $\alpha$ became more inhomogeneous. The observed $\alpha$ precipitation in the PWHT-1 and PWHT-2 specimens agrees well with Duerig et al.'s findings. At $1077 \mathrm{~K}\left(804{ }^{\circ} \mathrm{C}\right) \propto$ precipitates inhomogeneously as both fine and coarse plates, whereas upon aging at $873 \mathrm{~K}\left(600{ }^{\circ} \mathrm{C}\right)$ for 4 hours $\alpha$ precipitates homogeneously as small plates in the $\beta$-grains as evidenced in Figure 2(b). Fundamentally, there is no difference between nanoscale $\alpha$ precipitates observed in the solution-treated and aged specimens except for size and distribution.

The nanoscale $\alpha$ precipitates in the solution-treated specimens do not contribute to strengthening the FZ, which can be clearly seen in the hardness results for the solution-treated specimens and in the tensile results. Instead of providing strength, the fine $\alpha$ precipitates in the solution-treated samples could contribute to the brittle-like behavior and the degradation of strength compared to the as-welded specimens.

In summary, PWHT at $1077 \mathrm{~K}\left(804{ }^{\circ} \mathrm{C}\right)$ for 1 hour is insufficient to completely dissolve the $\omega$-phase formed in the FZ during cooling, but a two-step PWHT [1077 K $\left(804{ }^{\circ} \mathrm{C}\right)$ for 1 hour followed by aging at $873 \mathrm{~K}\left(600{ }^{\circ} \mathrm{C}\right)$ for 4 hours] completely eliminates $\omega$ and precipitates fine $\alpha$. This work suggests that longer durations of the overall PWHT promote $\omega$ dissolution and lower temperatures promote homogeneous precipitation of $\alpha$.

\section{CONCLUSIONS}

This research presents the effects of EB welding and two post-weld heat treatments on the mechanical behavior of Ti-5553. EB welding resulted in retained $\beta$ upon cooling in the FZ as well as the decomposition of $\beta$ to $\omega$ upon cooling. The $\omega$-phase imparted brittle behavior in the FZ in the as-welded condition due to compositional ordering as evidenced by HAADFSTEM. Solution treating at $1077 \mathrm{~K}\left(804{ }^{\circ} \mathrm{C}\right)$ for 1 hour (PWHT-1) provided no improvements in properties. In fact, due to the presence of grain boundary $\alpha$ and the residual $\omega$-phase, the tensile fracture strength was lower than that of the as-welded condition. Even though nanometer-scale $\alpha$ was present among the coarse $\alpha$, it provided no additional strength to the FZ because it was 

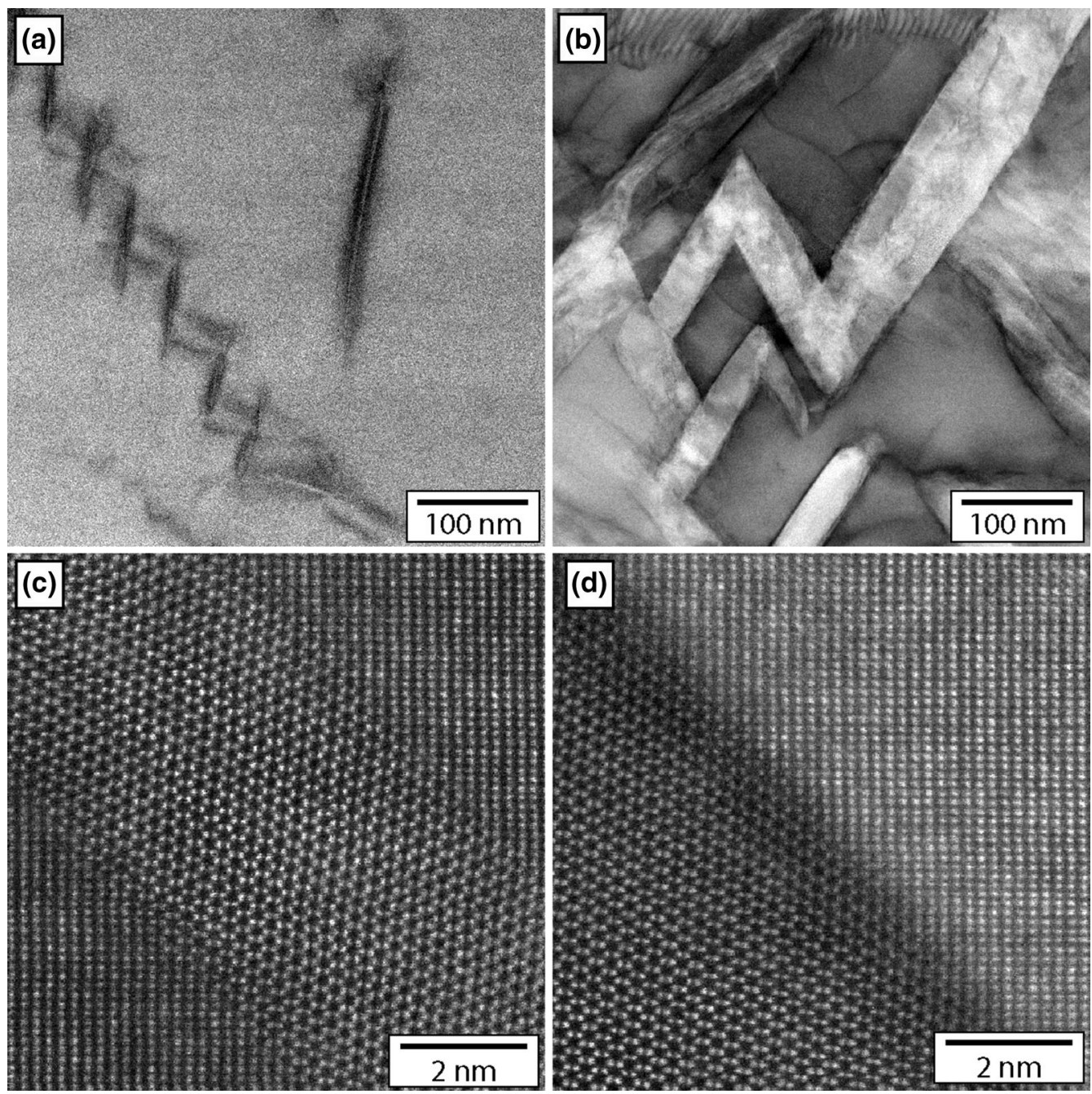

Fig. 10 - Bright field $(a, b)$ and atomic resolution high-angle annular dark field $(c, d)$ scanning transmission electron micrographs comparing the size of the $\alpha$ precipitates in the $(\mathrm{a}, \mathrm{c}) 1077 \mathrm{~K}\left(804{ }^{\circ} \mathrm{C}\right) / 1 \mathrm{~h}$ solution-treated and $(\mathrm{b}, \mathrm{d}) 1077 \mathrm{~K}\left(804{ }^{\circ} \mathrm{C}\right) / 1 \mathrm{~h}$ solution-treated and aged at $873 \mathrm{~K}$ $\left(600^{\circ} \mathrm{C}\right) / 4 \mathrm{~h}$. All images were oriented to the $[110]_{\beta}$ direction.

sparse and inhomogeneously distributed. Aging at $873 \mathrm{~K}\left(600{ }^{\circ} \mathrm{C}\right)$ for 4 hours after solution treatment (PWHT-2), however, improved the mechanical properties of the FZ compared to the as-welded condition. The improved mechanical properties are attributed to dissolution $\omega$, a dense network of fine $\alpha$ precipitates, and a more homogeneous microstructure. Overall, the results of this study illustrate that the FZ of EB-welded Ti-5553 can be significantly strengthened by a two-step aging treatment at $1077 \mathrm{~K}$ and $873 \mathrm{~K}\left(804{ }^{\circ} \mathrm{C}\right.$ and $\left.600{ }^{\circ} \mathrm{C}\right)$, and that a solitary solution treatment at $1077 \mathrm{~K}$ $\left(804{ }^{\circ} \mathrm{C}\right)$ is not beneficial towards strengthening.

\section{ACKNOWLEDGMENTS}

The authors thank the Loewy Family Foundation for financially supporting this project and three of the authors, (JCS) as a Loewy Graduate Fellow, (TP) as a Visiting Loewy Professor, and (WZM) through the
Loewy Professorship at Lehigh University. The authors would also like to acknowledge Dr. Martin P. Harmer of Lehigh University for his collaboration and the Office of Naval Research-Multidisciplinary University Research Initiative (ONR-MURI) under Grant No. N00014-11-1-0678 for financial support of CJM.

\section{REFERENCES}

1. G. Lütjering and J.C. Williams: Titanium, 2nd ed., Springer, Berlin, 2007.

2. J.D. Cotton, R.D. Briggs, R.R. Boyer, S. Tamirisakandala, P. Russo, N. Shchetnikov, and J.C. Fanning: J. Mater. Res., 2015, vol. 67 , pp. $1281-303$.

3. S.D. Bartus: Army Research Laboratory Technical Report ARLTR-4996, 2009.

4. J.C. Fanning: J. Mater. Eng. Perform., 2005, vol. 14, pp. 788-91.

5. J.C. Sabol, C.J. Marvel, M. Watanabe, T. Pasang, and W.Z. Misiolek: Scr. Mater., 2014, vol. 92, pp. 15-18.

6. D.W. Becker and W.A. Baeslack, III: Weld. J., 1980, vol. 124, pp. 85-92.

7. S. Mueller, C. Bratt, P. Mueller, J. Cuddy, and K. Shankar: Proc. ICALEO 2008 27th Int. Congr. Appl. Lasers Electro-Optics, 2008, pp. $846-54$. 
8. R. Mitchell, A. Short, T. Pasang, and G. Littlefair: Adv. Mater. Res., 2011, vol. 275, pp. 81-84.

9. J.C. Sabol, T. Pasang, W.Z. Misiolek, and J.C. Williams: J. Mater. Process. Technol., 2012, vol. 212, pp. 2380-85.

10. S. Shekhar, R. Sarkar, S.K. Kay, and A. Bhattacharjee: Mater. Des., 2015, vol. 66, pp. 596-610.

11. N.G. Jones, R.J. Dashwood, M. Jackson, and D. Dye: Acta Mater., 2009, vol. 57, pp. 3830-39.

12. A. Settefrati, M. Dehmas, G. Geandier, B. Appolaire, S. Audion, and J. Delfosse: Solid State Phenom., 2011, vol. 172, pp. 760-65.

13. D. Qin, Y. Li, S. Zhang, and L. Zhou: J. Alloy. Compd., 2016, vol. 663 , pp. $581-93$.

14. A. Dehghan-Manshadi and R.J. Dippenaar: Mater. Sci. Eng. A, 2011, vol. 528, pp. 1833-39.

15. N. Clément, A. Lenain, and P.J. Jacques: JOM, 2007, vol. 59, pp. 50-53.

16. S.K. Kar, A. Ghosh, N. Fulzele, and A. Bhattacharjee: Mater. Charact., 2013, vol. 81, pp. 37-48.

17. T. Schmidt, J. Tyson, and K. Galanulis: Exp. Tech., 2003, vol. 27, pp. 47-50.
18. T. Schmidt, J. Tyson, and K. Galanulis: Exp. Tech., 2003, vol. 27, pp. 22-26.

19. C. Sauer and G. Lütjering: Mater. Sci. Eng. A, 2001, vols. 319-321, pp. 393-97.

20. G. Lütjering, J. Albrecht, C. Sauer, and T. Krull: Mater. Sci. Eng. A, 2007, vols. 468-470, pp. 201-09.

21. A.W. Bowen: Scr. Metall., 1971, vol. 5, pp. 709-15.

22. A. Gysler, G. Lütjering, and V. Gerold: Acta Metall., 1974, vol. 22, pp. 901-09.

23. N.G. Jones, R.J. Dashwood, D. Dye, and M. Jackson: Mater. Sci. Eng. A, 2008, vol. 490, pp. 369-77.

24. S. Nag, R. Banerjee, R. Srinivasan, J.Y. Hwang, M. Harper, and H.L. Fraser: Acta Mater., 2009, vol. 57, pp. 2136-47.

25. S. Nag, Y. Zheng, R.E.A. Williams, A. Devaraj, A. Boyne, Y. Wang, P.C. Collins, G.B. Viswanathan, J.S. Tiley, B.C. Muddle, R. Banerjee, and H.L. Fraser: Acta Mater., 2012, vol. 60, pp. $6247-56$

26. T.W. Duerig, G.T. Terlinde, and J.C. Williams: Metall. Trans. A, 1980, vol. 11, pp. 1987-98. 